OPEN ACCESS

Edited by:

Yufei Ma,

Harbin Institute of Technology, China

Reviewed by:

Minchao Cui,

Northwestern Polytechnical

University, China

Anmin Chen,

Jilin University, China

*Correspondence:

Daming Dong

damingdong@hotmail.com

Specialty section:

This article was submitted to

Optics and Photonics,

a section of the journal

Frontiers in Physics

Received: 24 November 2021 Accepted: 04 January 2022

Published: 27 January 2022

Citation:

XuF, Ma S, Zhao C and Dong D (2022) Application of Molecular Emissions in

Laser-Induced Breakdown

Spectroscopy: A Review.

Front. Phys. 10:821528.

doi: 10.3389/fphy.2022.821528

\section{Application of Molecular Emissions in Laser-Induced Breakdown Spectroscopy: A Review}

\author{
Fanghao $\mathrm{Xu}^{1,2}$, Shixiang $\mathrm{Ma}^{1}$, Chunjiang Zhao ${ }^{1}$ and Daming Dong ${ }^{1 *}$ \\ ${ }^{1}$ National Research Center of Intelligent Equipment for Agriculture, Beijing Academy of Agriculture and Forestry Sciences, Beijing, \\ China, ${ }^{2}$ College of Mechanical and Electrical Engineering, Gansu Agricultural University, Lanzhou, China
}

Laser-induced breakdown spectroscopy (LIBS) with advantages of rapid, in situ, and little sample pretreatment has been used in various fields. However, LIBS technology remains challenging in the detection of halogens, isotopes, and samples with similar elements. Therefore, molecular emission was proposed to improve the detection ability of LIBS. In this review, we introduced molecular emissions formed by organic elements, oxidizable elements, and halogens. Then, molecular emission in different experiment parameters, such as the acquisition window, laser characters (laser energy, laser wavelength, and pulse duration), and ambient atmospheres, were discussed. In the end, we highlight the application of molecular emissions on element content determination, material type classification, and combustion and explosion process monitoring.

Keywords: laser-induced breakdown spectroscopy, molecular emissions, isotope, halogen, energetic samples, plastic samples, biomedical samples, process monitoring

\section{INTRODUCTION}

Laser-induced breakdown spectroscopy (LIBS) is an ideal spectroscopic technique for material component analysis. The advantages of a rapid, in situ, real-time and remote analysis, and simple sample preparation [1-3] extend LIBS to detection in various environments, such as the space [4,5], ocean $[6,7]$, nuclear reactors $[8,9]$, mines $[10,11]$, and in the metallurgical $[12,13]$ and industrial fields $[14,15]$. These studies are based on the atomic emissions in the spectra. However, atomic emissions still have several drawbacks, including 1) the matrix effect [16,] and self-absorption [17, 18] blocking accuracy for quantitation and 2) its unsuitability for the classification of matters with similar elemental compositions. To overcome these drawbacks, researchers have focused on molecular emission in recent years [19]. Moreover, molecular emission can monitor burning and exploding processes.

In recent years, molecular emission was mentioned in LIBS reviews of specific targets, such as organics [20], explosives [21], and combustion [22]. The formation mechanism and experimental parameters for molecular emission were not discussed. The purpose of this review was to summarize the application of laser-induced molecular emission in quantitative classification and process monitoring. To make the molecular emission application wellfounded, we summarized the molecular emission formation and how the experimental parameters influenced molecular emissions before the application. And, the framework of this review is shown in Figure 1. 


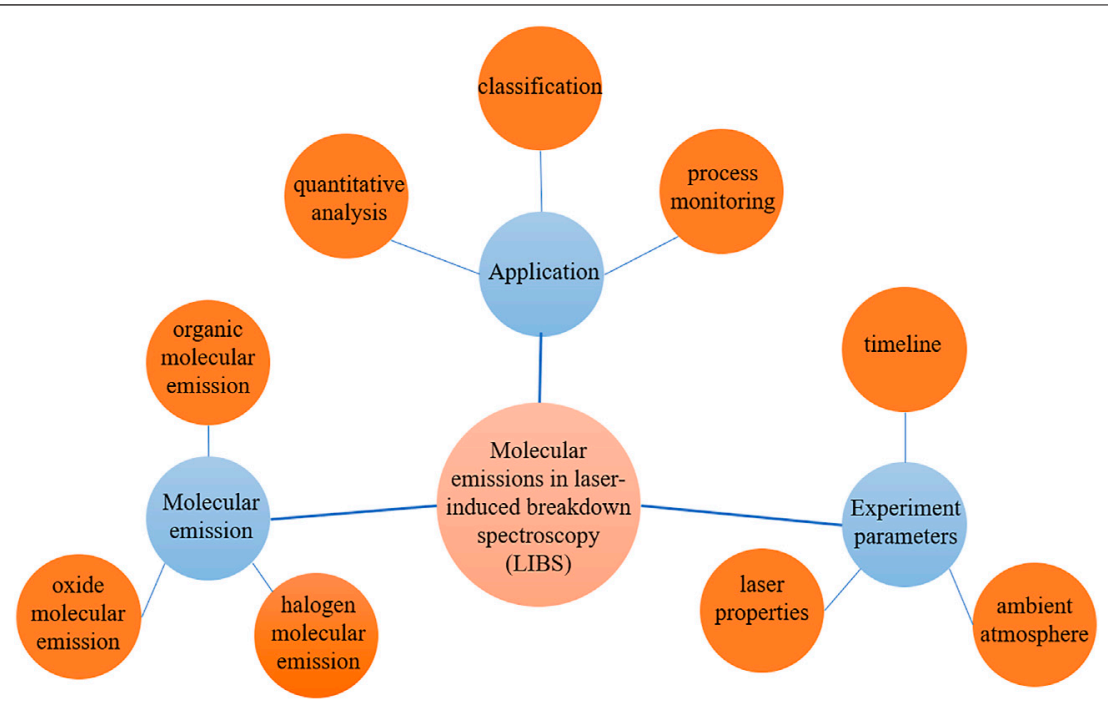

FIGURE 1 | Framework of this review.

\section{MOLECULAR EMISSIONS IN LIBS}

The characteristic molecular emission line radiates from the plasma induced by high irradiance (typically about $10^{10} \mathrm{~W} /$ $\mathrm{cm}^{2}$ ) and short pulse duration (typically $<10 \mathrm{~ns}$ ) laser, which is the same condition as that for atomic and ionic emissions. Different from the atomic and ionic emissions, however, there are two routes for molecular emissions: 1) recombination of the atomic and ionic species in the plasma and/or 2) direct emission by the molecular fragments separate from the matrix. For recombination routes, the species in the plasma contain molecular fragments and atomic and ionic species induced from the sample and surroundings, and the process can be described as plasma chemistry [20].

The molecular emission can be divided into organic element molecular emissions, oxide molecular emissions, and halogen element molecular emissions by the composition of the molecular radical. The band system and formation routes are listed in Table 1.

\section{Organic Element Molecular Emissions}

Carbon $(\mathrm{C})$, hydrogen $(\mathrm{H})$, nitrogen $(\mathrm{N})$, and oxygen $(\mathrm{O})$ are the main organic elements and can combine to form diatomic molecular radicals, such as $\mathrm{CN}$ (cyanogen), $\mathrm{C}_{2}$ (carbon dimer), $\mathrm{CH}$ (methylidyne), $\mathrm{OH}$ (hydroxyl) and $\mathrm{NH}$ (amidogen), and so on.

$\mathrm{CN}$ molecular emissions can easily occur during laser ablation of carbonic matter in the air. This mainly comes from the recombination of the carbon and nitrogen atoms in the plasma [23].

$\mathrm{C}_{2}$ molecular emissions can also occur from the carbonic matter. However, they always require the presence of a carbon-carbon bond (C-C) or carbon-carbon double bond $(\mathrm{C}=\mathrm{C})$ in the matrix. This mainly comes from molecular fragments [24].
$\mathrm{CH}$ molecular emissions are common from the core of the combustion zone. $\mathrm{CH}$ emission can be directly released and formed by carbon and hydrogen species [25].

$\mathrm{OH}$ molecular emission can radiate from plasma that includes high amount of $\mathrm{H}$ and $\mathrm{O}$ species. Such as laser ablation materials containing high mount water $\left(\mathrm{H}_{2} \mathrm{O}\right)$ and hydroxide radical. And the $\mathrm{OH}$ molecular emission is generally low [26].

$\mathrm{NH}$ molecular emissions can radiate from the plasma with nitrogen and hydrogen species. These molecular emissions are commonly released in high hydrogen $(\mathrm{H})$ content materials induced by laser in the air and occur more commonly in the femtosecond-induced plasma [27].

\section{Oxide Molecular Emissions}

Metals and non-metals induced by lasers can combine with $\mathrm{O}$ to form oxide molecular emissions, such as aluminum monoxide (AlO), strontium monoxide (SrO), carbon monoxide (CO), boron monoxide (BO), and silicon monoxide $(\mathrm{SiO})$.

AlO molecular emission can occur when aluminum alloy undergoes laser ablation in ambient air [28], combining $\mathrm{Al}$ and $\mathrm{O}$ in the plasma. $\mathrm{SrO}, \mathrm{CO}, \mathrm{BO}$, and $\mathrm{SiO}$ molecular emissions are similar to the $\mathrm{AlO}$ molecular emission.

\section{Halogen Molecular Emissions}

Halogen is difficult to detect in LIBS due to the weak emission, which overlaps with the matrix, and because of their ultraviolet spectral region. The emissions of diatomic molecules of halogens, such as fluorine $(\mathrm{F})$, chlorine $(\mathrm{Cl})$, bromine $(\mathrm{Br})$, and iodine (I), combined with alkali earth elements substantially increases the sensitivity for halogen detection. Alkali earth-halogen molecular emissions mainly recombined in the plasma [29]. 
TABLE 1 | Molecular emissions used in this review.

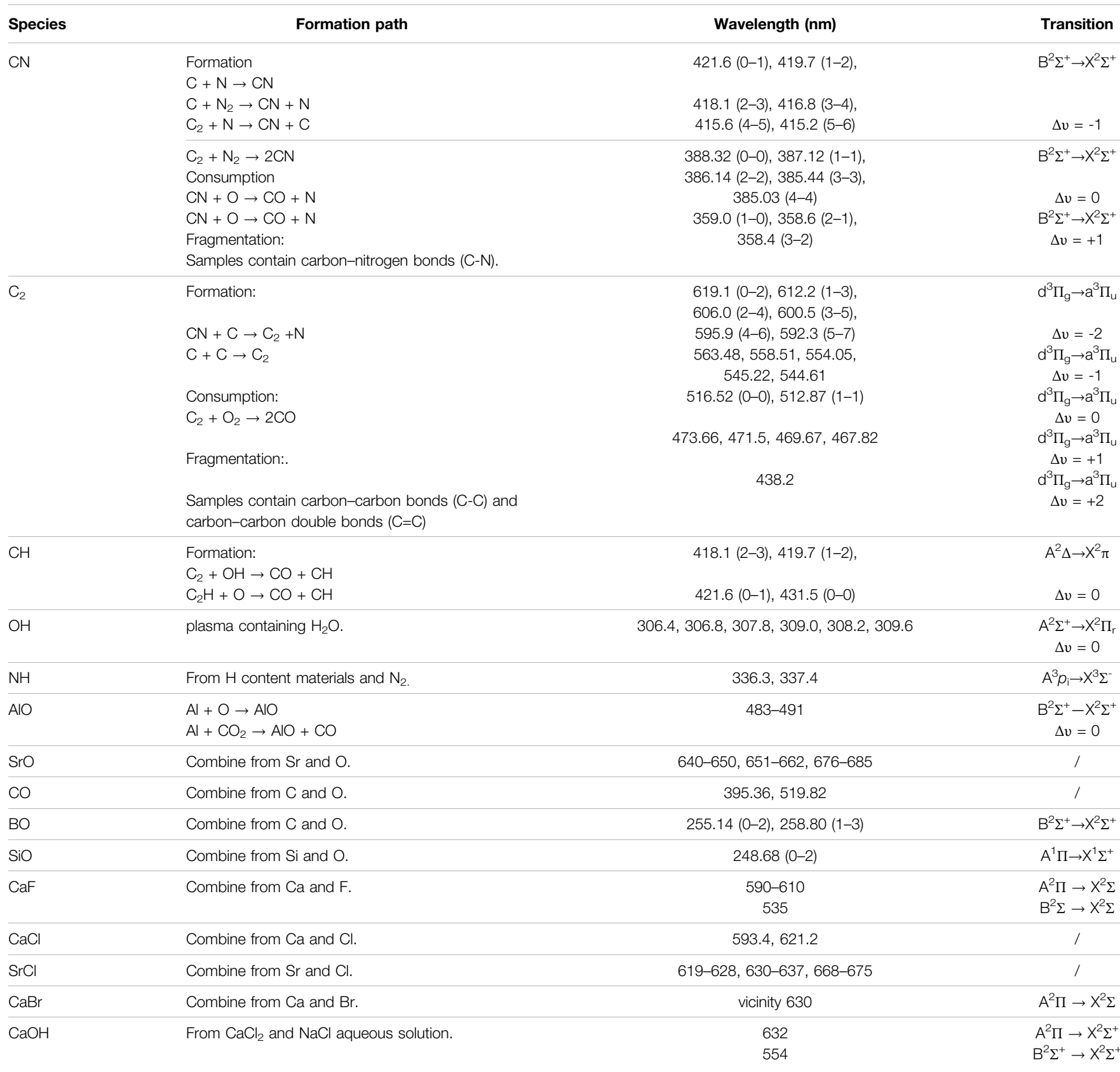

\section{EXPERIMENTAL PARAMETERS FOR MOLECULAR EMISSION}

The same matters can radiate different molecular emissions due to the fact that plasma chemistry can be strongly influenced by experimental parameters [30], such as the timeline, laser characteristics (laser energy, pulse duration, and laser wavelength), and ambient air, which are the main influence factors. And, most studies were about $\mathrm{CN}$ and $\mathrm{C}_{2}$ molecular emissions. The $\mathrm{CN}$ emission is obtained by recombination, while the $\mathrm{C}_{2}$ emission is principally fragmented directly from the matrix. In this part, we will discuss the influence though $\mathrm{CN}$ and $\mathrm{C}_{2}$ molecular emissions. The formation route of $\mathrm{CN}$ and $\mathrm{C}_{2}$ molecular emissions is shown in Figure 2.

\section{Timeline of Molecular Emission}

Spectral lines emitted from the plasma are changed continuously because of the electron density and temperature decrease during the expansion. Over the duration of the plasma's persistence, the prevailing emitting species changes from ions to atoms, and to molecules in the ns LIB spectrum [31]. Furthermore, the lifetimes of the molecular emissions from the laser-induced plasma are much longer and later than the ionic and atomic emissions [32]. The molecular 


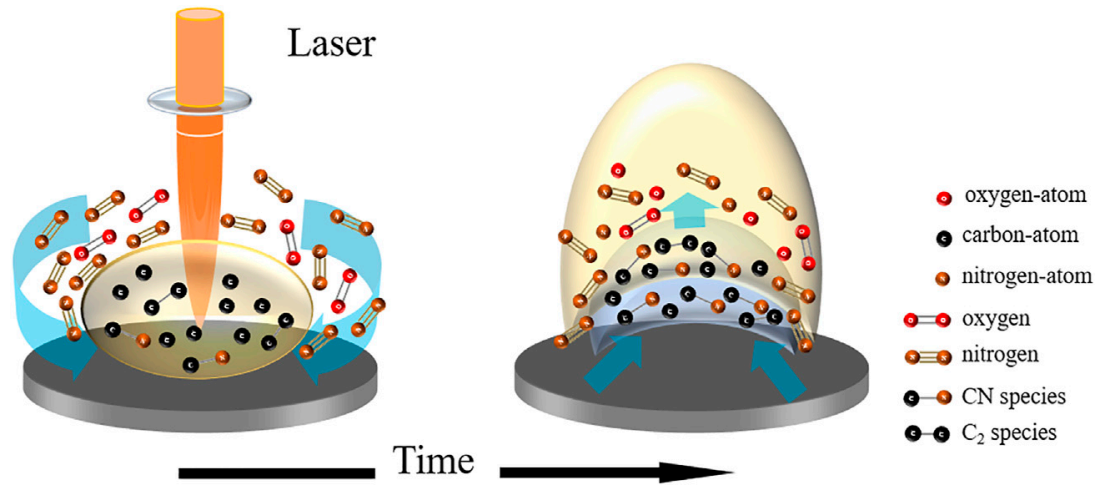

FIGURE 2 | Formation routes of $\mathrm{CN}$ and $\mathrm{C}_{2}$ molecular emissions. Laser ablate sample, atomizing carbon-atom and nitrogen-atom, fragmenting $\mathrm{CN}_{\text {and }} \mathrm{C}_{2}$ species from the sample, and atomizing nitrogen-atom and oxygen-atom from ambient gas. Species from the sample and surroundings combining new molecular species in the plasma.

emission signal acquisition windows are in delay time $0.5-5 \mu \mathrm{s}$ and gate width $0.5-1$ F06Ds in experiments, generally [33-35]. For CN molecular emissions, Fernandez-Bravo et al. [30] obtained precise time-resolved $\mathrm{CN}$ emissions. The results showed that $\mathrm{CN}$ emissions exhibited large behavior differences among organic compounds.

\section{Laser Characteristics for Molecular Emission}

In the LIBS system, the laser used to ablate the sample can be described by three characteristics: laser energy, pulse duration, and laser wavelength. As mentioned before that molecular species is produced at the timeline where the plasma temperature is low, the excitation of the molecular emission can be enhanced by reducing the heating effect of the laser with the materials.

When the laser energy reaches the ablation threshold of the material and vaporized it, the remaining energy is used to excite the vaporized materials to the upper state, and then the plasma is generated. Serrano et al. [36] showed that with a laser energy of increasing strength, greater energy will be used to atomize the material after reaching the ablation threshold, resulting in less molecular species in the plasma. And, they represented the atomization by the intensity ratio of $\mathrm{CN} / \mathrm{C}_{2}$. Thus, to achieve more molecular fragments in the plume, it is helpful to have the laser energy close to the sample ablation threshold.

The other two characteristics, pulse duration and laser wavelength, depend on the native properties of lasers. Research studies have indicated that a shorter pulse duration and ultraviolet (UV) wavelength of the laser pulse can improve the spectral quality of molecular emission.

For the duration of the laser pulse, Junjuri et al. [37] concluded that femtosecond (fs) lasers are more suitable for the excitation of molecular emission than nanosecond (ns) lasers owing to shorter interacting time between the laser and materials. Rao et al. [33] showed that fs lasers can induce molecular emission earlier than ns counterparts, and the emission intensity can be stronger [38]. The reused Figure 3 shows that $\mathrm{CN}$ and $\mathrm{C}_{2}$ molecular emissions in $\mathrm{ns}$ and fs laser-induced spectra [34]. The intensity of ionic and atomic emissions is higher in the ns laser-induced spectrum, but molecular emissions are higher in the fs laser-induced spectrum. De Lucia et al. [39] discovered that the fs laser can reduce the disturbance due to inducing less species from the ambient atmosphere. Further, Shaik et al. [40] concluded that fs lasers can introduce less substrate interferences in molecular emissions.

For the wavelength of the laser pulse, the most commonly used wavelengths are the infrared (IR) laser pulses $(1,064 \mathrm{~nm})$ and the second harmonic, visible (Vis) laser pulses $(532 \mathrm{~nm})$ of the Nd:YAG laser. The short wavelength can interact with the sample more efficiently. Baudelet et al. ablated organic materials with UV pulses $(266 \mathrm{~nm})$ delivered by a quadrupled Nd:YAG laser, comparing the plasmas induced by the $4 \mathrm{~ns}$ IR laser with energy from 1-5 mJ [41]. The results demonstrated that ns UV pulses with a low fluence can produce native molecular fragments efficiently and a minimized recombination with ambient air [42]. The middleinfrared (M-IR) laser pulse $(10.591 \mu \mathrm{m}, 3.16 \mathrm{~J})$ is also used in molecular emission studies $[43,44]$.

\section{Ambient Atmospheres for Molecular Emission}

The $\mathrm{N}$ and $\mathrm{O}$ atoms in the air (approximately $80 \% \mathrm{~N}_{2}$ and $20 \% \mathrm{O}_{2}$ ) are also excited by the laser and participate in the plasma chemistry. To make more accurate use of molecular emission, it is necessary to study the atmosphere condition. Mousavi et al. [23] studied the molecular emissions of $\mathrm{CN}$ and $\mathrm{C}_{2}$ in ambient nitrogen $\left(\mathrm{N}_{2}\right)$, air, oxygen $\left(\mathrm{O}_{2}\right)$, and argon (Ar) atmospheres by the ns laser pulse. The results showed that the intensity of the $\mathrm{CN}$ and $\mathrm{C}_{2}$ molecular emissions decreased owing to the increased $\mathrm{O}_{2}$ content. In the $\mathrm{N}_{2}$ environment, the $\mathrm{CN}$ molecular emission intensity increased owing to the recombination of $\mathrm{C}$ and $\mathrm{N}$. In the inert gas, Ar atmosphere, the vibrational temperatures of both $\mathrm{CN}$ and $\mathrm{C}_{2}$ had the highest values. Researchers have also studied $\mathrm{CN}$ and $\mathrm{C}_{2}$ in helium $(\mathrm{He})$ and carbon dioxide $\left(\mathrm{CO}_{2}\right)$ atmospheres $[45,46]$.

In addition, molecular emission is influenced by different pressures of the surrounding atmosphere. Delgado et al. [47] 

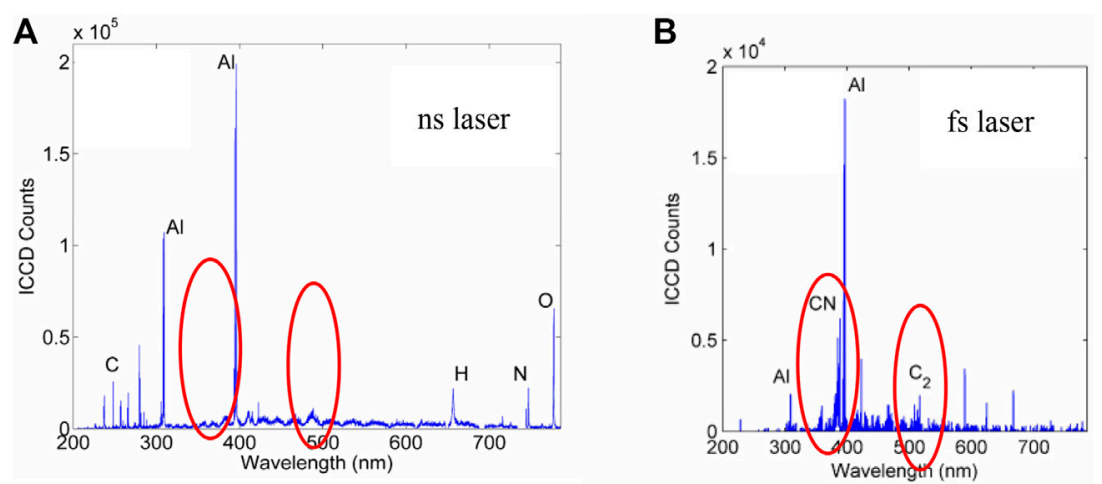

FIGURE 3 | (A) Nanosecond LIBS signal obtained from TNT on an aluminum substrate. The detection gate delay and width values were 1 and $2 \mu$ s, respectively. (B) Femtosecond LIBS signal obtained from TNT on an aluminum substrate, over the complete detection wavelength range. The detection gate delay and width values were $100 \mathrm{~ns}$ and $1 \mu \mathrm{s}$, respectively [34].
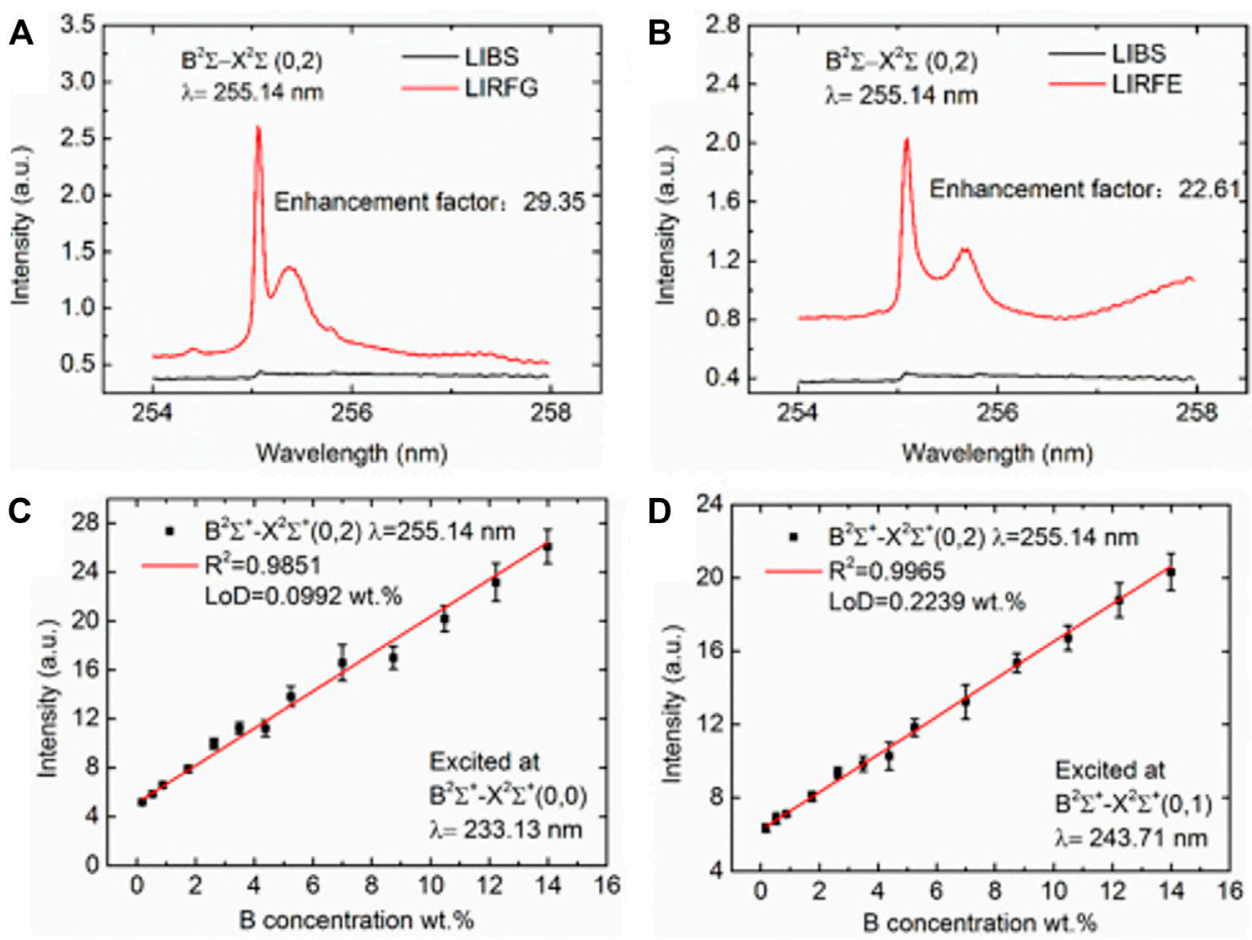

FIGURE 4 | Spectral comparisons of (A) LIBS and LIRFG and (B) LIBS and LIRFE. Calibration curves of BO in (C) LIRFG and (D) LIRFE. [50].

investigated the molecular emissions at high vacuum $\left(<10^{-1} \mathrm{mbar}\right)$ to high pressure $(1,000 \mathrm{mbar})$. The results showed that emissions were dominated by ionic and atomic emissions at high vacuum. The $\mathrm{C}_{2}$ and $\mathrm{CN}$ emissions increased rapidly when the pressure was increased in the range between 10-100 mbar. While the pressure surpassed 100 mbar, the $\mathrm{C}_{2}$ and $\mathrm{CN}$ emissions decreased. The authors attributed this observation to there being less species collision in the plasma at a low pressure, leading to less reaction in the plasma.

\section{APPLICATION OF MOLECULAR EMISSION \\ Quantitative Analysis by Molecular Emission}

LIBS analysis through atomic and ionic emissions provides insufficient results when the self-absorption appearance and/or disturbed by other elements. In this part, we will discuss the role of molecular emissions in quantitative analysis [48]. 


\subsubsection{Molecular Emission for Quantitative Analysis}

Ionic and atomic emissions are rarely used for the quantitative analysis of high-content samples because of the strong selfabsorption effect. The molecular emission from LIBS can be a promising solution. Zhu et al. [49] collected the BO molecular emissions from a mixture of $\mathrm{H}_{3} \mathrm{BO}_{3}$ and $\mathrm{C}_{6} \mathrm{H}_{12} \mathrm{O}_{6} \cdot \mathrm{H}_{2} \mathrm{O}$ in the powder form. The root mean square error of prediction (RMSEP) and the mean prediction error (MPE) for the genetic algorithm and partial least square regression combination model (GAPLSR) were $0.8667 \mathrm{wt} . \%$ and $10.9685 \%$ by $\mathrm{BO}$ molecular emissions, respectively. There was much better linearity in the molecular emission than the atomic emission of B I (249.68, $249.77,208.88$, and $208.96 \mathrm{~nm}$ ), owing to the much lower selfabsorption effect. However, the intensity of molecular emissions is much lower, which means that there is still room for further improvement in the calibration of the molecular emission. Guo et al. [50] assisted LIBS with laser-induced radical fluorescence (LIBS-LIRF) to establish calibration of BO molecular emissions. The results showed that the enhancement factors are 29.35 for vibrational ground state excitation (LIRFG) and 22.61 for vibrational excited state excitation separately (LIRFE). The LIRFG had better sensitivity, with a limit of detection (LoD) of 0.0993 wt.\%, while the LIRFE was more accurate, with a root mean square error of cross validation (RMSECV) of 0.2514 wt.\%. The enhancement factors and quantitative results are shown in Figure 4. Zhang et al. [51] used LIBS assisted with laser-induced molecular fluorescence (LIBS-LIMF) to establish the calibration of the silicon content by silicon monoxide ( $\mathrm{SiO}$ ) molecular emission in micro-alloyed steel. The determination coefficient $R^{2}=0.988, \mathrm{LoD}=187 \mu \mathrm{g} / \mathrm{g}$, and RMSECV of $0.046 \mathrm{wt} . \%$. In addition, $\mathrm{CaOH}$ emission can be used to detect the Ca content in underwater conditions. The results showed a LoD $=2.46 \mathrm{ppm}$ with good linearity in a range from 5 to $2000 \mathrm{ppm}$ [52].

\subsubsection{Molecular Isotopic Emission for Quantitative Analysis}

LIBS has been used in nuclear isotope safeguard inspection $[8,9$, 53], but the tiny shifts between the isotopic atomic or ionic emissions can only be detected by high-resolution detectors and/ or in low-pressure environments. Laser ablation molecular isotopic spectrometry (LAMIS) has been proposed as an efficient isotope detection method owing to the larger isotopic shifts. For example, the boron isotopic $\left({ }^{11} \mathrm{~B}-{ }^{10} \mathrm{~B}\right)$ shift in atomic emission is 2 picometer (pm). However, for ${ }^{10} \mathrm{BO}$ and ${ }^{11} \mathrm{BO}$, the isotopic shifts extend from $0.74 \mathrm{~nm}$ to $5-8 \mathrm{~nm}$. A partial least square (PLS) regression was used to further analyze the isotopic abundance approximately from 1 to $100 \%$ content of ${ }^{11} \mathrm{~B}, R^{2}=$ 0.9993 [54]. Furthermore, researchers at the Lawrence Berkeley National Laboratory detected the isotopes of hydrogen $(\mathrm{H})$, boron (B), carbon (C), and oxygen (O) with LAMIS in reference [55]. Mao et al. [56] performed the isotopic analysis of solid Sr-containing samples $\left({ }^{86} \mathrm{Sr},{ }^{87} \mathrm{Sr}\right.$, and $\left.{ }^{88} \mathrm{Sr}\right)$ in ambient air at normal pressure. The results showed that the radial spectra of $\mathrm{SrO}$ and strontium fluoride $(\mathrm{SrF})$ molecular emissions provided a well-resolved spectrogram for the naturally occurring Sr isotopes. Chirinos et al. [57] detected ${ }^{13} \mathrm{C}$ from a graphite sample at a distance of $36 \mathrm{~m}$ by fs filaments - laser ablation molecular isotopic spectrometry (F-2-LAMIS) with a standardless quantification approach. The authors concluded that F-2-LAMIS can be a method to remote sense isotopes in the field.

In addition, the second laser enhance technology has been used in LAMIS. Brown et al. [58] utilized middle-infrared (MidIR) laser pulses $(10.6 \mu \mathrm{m})$ for the second pulse, referred to as double-pulse LAMIS (DP-LAMIS) to determine the relative abundance of ${ }^{11} \mathrm{~B}$ and ${ }^{10} \mathrm{~B}$. The results showed $R^{2}>0.960$ and LoD $<2.3 \%$. Akpovo et al. [59] combined LIBS and molecular laser-induced fluorescence (MLIF) to selectively enhance the BO molecular emission $(253-271 \mathrm{~nm})$. The LoD was $1.88 \%$ by PLS regression, which was better than the single pulse result of $2.45 \%$.

\subsubsection{Halogen Molecular Emission for Quantitative Analysis}

The emission of halogen elements (such as $\mathrm{F}, \mathrm{Cl}, \mathrm{Br}$, and I) is weak in LIBS because they require a high excitation energy and cannot reach a good quantitative accuracy. Alkali earth-halogen molecular emission can be another choice to detect the halogen elements.

Dietz et al. [60] quantified the $\mathrm{Cl}$ content, a harmful element present in cement-based materials, by calcium-monochloride $(\mathrm{CaCl})$ molecular emission. The results showed an $\mathrm{LoD}=$ 0.075 wt.\%, which was below the critical threshold of 0.2 wt.\% of chlorides related to the cement in reinforced concrete. Álvarez et al. [61] investigated the fluorite $\left(\mathrm{CaF}_{2}\right)$ mass-content from 2.3 to $60 \%$ by calcium fluoride $(\mathrm{CaF})$ molecular emissions in powdered ore samples. Further, CaF molecular emission was used to studied $\mathrm{Cu}$ matrix samples containing different $\mathrm{F}$ concentrations (between 50 and $600 \mu \mathrm{g} / \mathrm{g}$ ) with variable amounts of $\mathrm{Ca}$ in the copper ore [62]. The results showed good linear relationships between the $\mathrm{CaF}$ molecular emission and $\mathrm{F}$ content. This methodology was extended in Ca-free samples by nebulizing a Ca-containing solution on the surface to form CaF molecular emission [63]. The LoD was $50 \mu \mathrm{g} / \mathrm{g}$, similar to the Ca-containing samples. For other researchers, Tang et al. [64] used strontium fluoride $(\mathrm{SrF})$ molecular emissions to detect the fluorine $(\mathrm{F})$ content. The results showed that LoD = $5 \mathrm{ppm}, \mathrm{R} 2=0.9933$, and RMSECV $=0.0049$ wt. $\%$. In water condition [65], LoDs of $\mathrm{F}$ and $\mathrm{Cl}$ elements detected by $\mathrm{CaF}$ and $\mathrm{CaCl}$ molecular emissions were $0.38 \mathrm{mg} / \mathrm{L}$ and $1.03 \mathrm{mg} / \mathrm{L}$, respectively. In addition, $\mathrm{Br}$ and $\mathrm{I}$ amounts were studied by molecular emission [66].

\section{Classification by Molecular Emission}

There are many research studies on classification analysis based on molecular emission. We summarized the research studies on the energetic materials, plastics, and biomedical samples.

\subsubsection{Energetic Sample Classification}

The direct chemical detection of energetic materials and explosives in real time is a particularly challenging problem. LIBS is a suitable technology to detect energetic materials. The first research study on explosives was reported by the U.S. Army Research Laboratory. De Lucia et al. [67] observed that the laserproduced plasma did not initiate any of the energetic materials and could be used to identify explosives. The $C_{2}$ molecular 
emission and the $\mathrm{H}, \mathrm{O}$, and $\mathrm{N}$ emission intensity ratios were the necessary parameters to identify the explosive [68]. In addition, the relationship between the various kinds of explosives and plasma emission could be established by the ratio of the atomic/ molecular emission intensities and the $\mathrm{CN}$ and $\mathrm{C}_{2}$ molecular emission decay rates with time [39]. Furthermore, the double pulse could improve the discrimination of explosives by decreasing the contributions of atmospheric $\mathrm{N}_{2}$ and $\mathrm{O}_{2}$ to the LIBS signal in the remote and on-line ways [69]. Partial least square discriminant analysis (PLS-DA) was used for distinguishing explosives at $50 \mathrm{~m}$. The results showed that the correct classification rate was $80 \%$, and the false positive rate remained at $7.8 \%$ [70].

For other research studies, Moros et al. [71] imported the original intensities of the most relevant emission signals (C:CN: $\left.\mathrm{C}_{2}: \mathrm{H}: \mathrm{N}: \mathrm{O}\right)$ to different machine learning classifiers. False positive and false negative rates better than 5\% were achieved. Yang et al. [72] captured three commonly used explosives (RDX, HMX, and PETN) molecular emissions in the long-wave infrared region (LWIR; range from 5.6 to $10 \mu \mathrm{m})$. The results showed that molecular emission signatures in the LWIR region could rapidly identify the different explosives.

Other energetic materials, such as solid propellants and petroleum, can also be studied by molecular emission. Solid propellants chemical aging is one of the most important problems for assessing the shelf-life of chemical propellants. Farhadian et al. [73] investigated and compared the $\mathrm{CN}$ and AlO molecular emissions of different kinds of solid propellants. The intensity ratios of the molecular emissions $\left(\mathrm{CN}, \mathrm{C}_{2}\right.$, and $\left.\mathrm{AlO}\right)$ were also considered [74]. El-Hussein et al. [75] studied the different grades of petroleum crude oil by $\mathrm{C} 2$ and $\mathrm{CN}$ molecular emission. The results showed that the $\mathrm{C}_{2}$ and $\mathrm{CN}$ molecular emissions were related to the American Petroleum Institute (API) gravity values of the various oil samples with the possibility of identifying the API gravity values of unknown oil samples.

\subsubsection{Plastic Sample Classification}

LIBS technology is not affected by the plastic shape and surface contaminants and can be used in online, rapid detection in industrial applications. The intensity ratio of molecular emission can be used to complete the identification of different types of plastics without an algorithm model. Anzano et al. [76] studied four kinds of plastic samples. The ratios of $\mathrm{C}_{2} / \mathrm{C}$ could be used to classify those plastic samples. Barbier et al. [46] investigated plastic samples in the $\mathrm{He}$ atmosphere. The results showed that the plot of $\mathrm{C}_{2} / \mathrm{He}$ against $\mathrm{CN} / \mathrm{He}$ was sufficient to identify the four groups of plastics employed in this study.

Researchers combine emission intensity ratios with statistical and stoichiometric methods to plastic samples. Banaee et al. [77] studied six plastic samples by ratios of the emission lines and molecular bands were analyzed by k-nearest neighbors $(\mathrm{KNN})$ and soft independent modeling of class analogy (SIMCA). The results showed the average classification accuracies of $98 \%$ for $\mathrm{KNN}$ and $92 \%$ for SIMCA. Further, Banaee et al. [78] input the ratios of the $\mathrm{CN}$ and $\mathrm{C}_{2}$ molecular emissions, and the atomic emissions of $\mathrm{C}, \mathrm{N}, \mathrm{Cl}, \mathrm{O}$, and $\mathrm{H}$ were discriminated by discriminant function analysis (DFA) with the accuracy of $99 \%$. Junjuri et al. [37] used an fs laser to enhance the effect of distinguishing the plastics by the principal component analysis (PCA) and artificial neural network (ANN), and the discriminant accuracy was $100 \%$.

\subsubsection{Biomedical Samples Classification}

The development of reliable sensors to detect biological residuals is important for security terrorist activity and is a high priority for the military and homeland security. Gottfried et al. [79] collected the molecular emission of $\mathrm{CN}, \mathrm{C}_{2}$, and $\mathrm{CaOH}$ from bacterial residues in the aluminum substrate, and the intensity and ratio of the emission were each input into the PLS-DA model. The results showed that the intensity/ratio models were able to correctly identify more types of residues in the presence of interferents. Baudelet et al. [80, 81] collected the $\mathrm{CN}$ molecular emission from the native $\mathrm{CN}$ band in Escherichia coli by the fs laser, and the emissions could be used to identify the bacterium [81]. In a low- pressure $\mathrm{CO}_{2}$ atmosphere, Delgado et al. [45] analyzed adenine, glycine, pyrene, and urea mixed with carbons. The results indicated LIBS with a potential for exploring life in the space environment. Yang et al. [82] detected the solid pharmaceutical tablet of Tylenol and buffering in the ultraviolet/ visible/ NIR (UVN) range (200-1,100 nm) and LWIR (Longwave infrared) range $(5.6-10 \mu \mathrm{m})$, respectively. The molecular emissions were highly specific and could distinguish between tablets.

\section{Process Monitoring}

Molecular emission can identify intermediate chemical species among the combustion and explosive explosions in situ, which is helpful to understand the process. In this section, we summarized molecular emission research in combustion and explosion.

Molecular emissions of combustion intermediates can indicate the flame's structure and burning quality. Ghezelbash et al. [25] investigated the $\mathrm{CH}, \mathrm{CH}^{*}, \mathrm{C}_{2}$, and $\mathrm{CO}$ molecular emissions in different areas in the laminar diffusion of methanol, ethanol, and n-propanol alcohol flames. The strong molecular emissions of $\mathrm{CH}$ and $\mathrm{CH}^{*}$ were from the blue zones (with low combustion quality). Kotzagianni et al. [83] demonstrated that the $\mathrm{CN}$ molecular emissions at $388.3 \mathrm{~nm}$ can be used to study the radial and axial variation within the flames. $\mathrm{Li}$ et al. [84] concluded that the femtosecond filament-induced spectrum contained rich information about the $\mathrm{CN}, \mathrm{CH}$, and $\mathrm{C}_{2}$ molecular emissions from the combustion intermediates of the butane flame.

The explosive ignited by the laser is similar to optical breakdown, and the molecular emissions that radiated from the process can be used to study it. Rao et al. [33] induced seven explosive molecules utilizing $\mathrm{fs}$ and ns lasers in the air and argon atmosphere. They observed the intensity ratio of $\mathrm{CN} / \mathrm{C}_{2}$ emission increase with an increasing percentage of $\mathrm{O}$ atoms, indicating the oxygen balance of explosive molecules. They further concluded that the ratio of atomization/fragmentation could indicate the explosive properties. A similar research by Kalam et al. [85] found the ratios of $\left(\mathrm{CN}+\mathrm{C}_{2}\right)$ / $(\mathrm{C}+\mathrm{H}+\mathrm{N}+\mathrm{O})$ correlated well with the detonation parameters, namely, oxygen balance, velocity of detonation, detonation pressure, and chemical energy. It supported the understanding and improvement of the discrimination procedures for such hazardous materials. In addition, aluminum powder was added to molecular explosives to study its chemistry at high temperatures. Gottfried et al. [86] ablated cyclotrimethylenetrinitramine (RDX) mixed with aluminum power at $(0: 1,1: 1,2: 1$, and $4: 1)$. The results showed 
that $\mathrm{Al}$ could combine with $\mathrm{O}$ to generate $\mathrm{AlO}$ molecular emission, which reduced the oxidation reaction of the explosive and reduced the adequacy of the reaction.

\section{CONCLUSION AND PROSPECTS}

In this review, we overviewed experiment parameters and the application of molecular emissions. The results showed molecular emission is emitted from a time of low electron temperature and density in the plasma. The intensity is strong when the laser energy is close to the ablation threshold and UV laser wavelength $(266 \mathrm{~nm})$ in the ns laser system. In the counterparts, the fs laser can produce more abundant molecular emissions owing to less heating effect. The UV laser is economic and maintainable compared with the fs laser. We consider the UV laser maybe a better choice for molecular emission analysis. In addition, the ambient atmosphere should be considered in molecular emissions, such as $\mathrm{N}$ and $\mathrm{O}$ species in air surroundings. For the quantitative study, molecular emissions, including isotopic and halogen molecules, can detect a wider range of matter content. For the classification study, molecular emission can distinguish matters with similar elements, such as energetic materials, plastics, and biomedical samples. Furthermore, researchers studied the combustion process and characteristics of explosives and the degrees of explosion in situ and in real time.

\section{REFERENCES}

1. Fortes FJ, Moros J, Lucena P, Cabalín LM, Laserna JJ. Laser-induced Breakdown Spectroscopy. Anal Chem (2013) 85:640-69. doi:10.1021/ ac303220r

2. Fernández-Menéndez LJ, Méndez-López C, Alvarez-Llamas C, GonzálezGago C, Pisonero J, Bordel N. Spatio-temporal Distribution of Atomic and Molecular Excited Species in Laser-Induced Breakdown Spectroscopy: Potential Implications on the Determination of Halogens. Spectrochimica Acta B: At Spectrosc (2020) 168:105848. doi:10.1016/j.sab.2020.105848

3. Grégoire S, Motto-Ros V, Ma QL, Lei WQ, Wang XC, Pelascini F, et al. Correlation between Native Bonds in a Polymeric Material and Molecular Emissions from the Laser-Induced Plasma Observed with Space and Time Resolved Imaging. Spectrochimica Acta Part B: At Spectrosc (2012) 74-75:31-7. doi:10.1016/j.sab.2012.07.020

4. Wan X, Li CH, Wang HP, Xu WM, Jia JJ, Xin YJ, et al. Design, Function, and Implementation of China's First LIBS Instrument (MarSCoDe) on the Zhurong Mars Rover. At Spectrosc. (2021) 42:294-8. doi:10.46770/as. 2021.608

5. Wiens RC, Maurice S, Barraclough B, Saccoccio M, Barkley WC, Bell JF, et al. The ChemCam Instrument Suite on the Mars Science Laboratory (MSL) Rover: Body Unit and Combined System Tests. Space Sci Rev (2012) 170: 167-227. doi:10.1007/s11214-012-9902-4

6. Guirado S, Fortes FJ, Lazic V, Laserna JJ. Chemical Analysis of Archeological Materials in Submarine Environments Using Laser-Induced Breakdown Spectroscopy. On-Site Trials in the Mediterranean Sea. Spectrochimica Acta Part B: At Spectrosc (2012) 74-75:137-43. doi:10.1016/j.sab.2012.06.032

7. Michel APM, Lawrence-Snyder M, Angel SM, Chave AD. Laser-induced Breakdown Spectroscopy of Bulk Aqueous Solutions at Oceanic Pressures: Evaluation of Key Measurement Parameters. Appl Opt (2007) 46:2507-15. doi:10.1364/Ao.46.002507

8. Singh M, Sarkar A, Banerjee J, Bhagat RK. Analysis of Simulated High Burnup Nuclear Fuel by Laser Induced Breakdown Spectroscopy.
Molecular emission is a kind of useful spectral line in LIBS; the study can further focus on detection of halogens, isotopes, and organic samples in the field. However, the complex radiation process confined the application LIBS. To apply laser-induced molecular emission in the field, it is necessary to study the molecular formation mechanism and optimize the parameters of the experimental system, reducing the disturbance of the ambient.

\section{AUTHOR CONTRIBUTIONS}

FX helped with the writing and editing of the original draft. FX and SM helped organize the draft. CZ carried out the investigation. DD contributed to investigation, methodology, and conceptualization.

\section{FUNDING}

This research was financially supported by the Distinguished Young Scientists Program of Beijing Natural Science Foundation (JQ19023) and the Distinguished Scientist Development Program of the Beijing Academy of Agriculture and Forestry Sciences (JKZX201904). This review also funded by National \& Local Joint Engineering Laboratory For Agricultural Internet of Things (PT2021-06).

Spectrochimica Acta Part B: At Spectrosc (2017) 132:1-7. doi:10.1016/j. sab.2017.03.012

9. Doucet FR, Lithgow G, Kosierb R, Bouchard P, Sabsabi M. Determination of Isotope Ratios Using Laser-Induced Breakdown Spectroscopy in Ambient Air at Atmospheric Pressure for Nuclear Forensics. J Anal At. Spectrom (2011) 26: 536-41. doi:10.1039/c0ja00199f

10. Balaram V. Rare Earth Elements: A Review of Applications, Occurrence, Exploration, Analysis, Recycling, and Environmental Impact. Geosci Front (2019) 10:1285-303. doi:10.1016/j.gsf.2018.12.005

11. Rifai K, Laflamme M, Constantin M, Vidal F, Sabsabi M, Blouin A, et al. Analysis of Gold in Rock Samples Using Laser-Induced Breakdown Spectroscopy: Matrix and Heterogeneity Effects. Spectrochimica Acta Part B: At Spectrosc (2017) 134:33-41. doi:10.1016/j.sab.2017.06.004

12. Dong F-Z, Chen X-L, Wang Q, Sun L-X, Yu H-B, Liang Y-X, et al. Recent Progress on the Application of LIBS for Metallurgical Online Analysis in China. Front Phys (2012) 7:679-89. doi:10.1007/s11467-012-0263-y

13. Hudson SW, Craparo J, De Saro R, Apelian D. Applications of Laser-Induced Breakdown Spectroscopy (LIBS) in Molten Metal Processing. Metall Materi Trans B (2017) 48:2731-42. doi:10.1007/s11663-017-1032-7

14. Lopez-Moreno C, Amponsah-Manager K, Smith BW, Gornushkin IB, Omenetto N, Palanco S, et al. Quantitative Analysis of Low-alloy Steel by Microchip Laser Induced Breakdown Spectroscopy. J Anal At. Spectrom (2005) 20:552-6. doi:10.1039/b419173k

15. Noll R, Fricke-Begemann C, Connemann S, Meinhardt C, Sturm V. LIBS Analyses for Industrial Applications - an Overview of Developments from 2014 to 2018. J Anal At. Spectrom (2018) 33:945-56. doi:10.1039/c8ja00076j

16. Sallé B, Cremers DA, Maurice S, Wiens RC. Laser-induced Breakdown Spectroscopy for Space Exploration Applications: Influence of the Ambient Pressure on the Calibration Curves Prepared from Soil and clay Samples. Spectrochimica Acta Part B: At Spectrosc (2005) 60:479-90. doi:10.1016/j.sab.2005.02.009

17. Bulajic D, Corsi M, Cristoforetti G, Legnaioli S, Palleschi V, Salvetti A, et al. A Procedure for Correcting Self-Absorption in Calibration Free-Laser Induced Breakdown Spectroscopy. Spectrochimica Acta Part B: At Spectrosc (2002) 57: 339-53. doi:10.1016/S0584-8547(01)00398-6 
18. El Sherbini AM, El Sherbini TM, Hegazy H, Cristoforetti G, Legnaioli S, Palleschi V, et al. Evaluation of Self-Absorption Coefficients of Aluminum Emission Lines in Laser-Induced Breakdown Spectroscopy Measurements. Spectrochimica Acta Part B: At Spectrosc (2005) 60:1573-9. doi:10.1016/j.sab.2005.10.011

19. Dong M, Mao X, Gonzalez JJ, Lu J, Russo RE. Time-resolved LIBS of Atomic and Molecular Carbon from Coal in Air, Argon and Helium. J Anal At. Spectrom (2012) 27:2066-75. doi:10.1039/c2ja30222e

20. Moros J, Laserna J. Laser-induced Breakdown Spectroscopy (LIBS) of Organic Compounds: A Review. Appl Spectrosc (2019) 73:963-1011. doi:10.1177/ 0003702819853252

21. Gottfried JL, De Lucia FC, Jr., Munson CA, Miziolek AW. Laser-induced Breakdown Spectroscopy for Detection of Explosives Residues: A Review of Recent Advances, Challenges, and Future Prospects. Anal Bioanal Chem (2009) 395:283-300. doi:10.1007/s00216-009-2802-0

22. Li B, Zhang D, Liu J, Tian Y, Gao Q, Li Z. A Review of Femtosecond LaserInduced Emission Techniques for Combustion and Flow Field Diagnostics. Appl Sci (2019) 9:1906. doi:10.3390/app9091906

23. Mousavi SJ, Hemati Farsani M, Darbani SMR, Mousaviazar A, Soltanolkotabi M, Eslami Majd A. CN and $C_{2}$ Vibrational Spectra Analysis in Molecular LIBS of Organic Materials. Appl Phys B (2016) 122:106. doi:10.1007/s00340-0166371-6

24. Harilal SS, Issac RC, Bindhu CV, Nampoori VPN, Vallabhan CPG. Spatial Analysis of Band Emission from Laser Produced Plasma. Plasma Sourc Sci. Technol. (1997) 6:317-22. doi:10.1088/0963-0252/6/3/008

25. Ghezelbash M, Majd AE, Darbani SMR, Mousavi SJ, Ghasemi A, Tehrani MK. Spatial Investigation of Plasma Emission from Laminar Diffusion Methanol, Ethanol, and N-Propanol Alcohol Flames Using LIBS Method. Appl Phys B (2017) 123:36. doi:10.1007/s00340-016-6615-5

26. Wilson WE. A Critical Review of the Gas-phase Reaction Kinetics of the Hydroxyl Radical. J Phys Chem Reference Data (1972) 1:535-73. doi:10.1063/1.3253102

27. Serrano J, Moros J, Laserna JJ. Exploring the Formation Routes of Diatomic Hydrogenated Radicals Using Femtosecond Laser-Induced Breakdown Spectroscopy of Deuterated Molecular Solids. J Anal At. Spectrom (2015) 30:2343-52. doi:10.1039/c5ja00192g

28. Wang Q, Chen A, Xu W, Zhang D, Wang Y, Li S, et al. Effect of Lens Focusing Distance on AlO Molecular Emission from Femtosecond Laser-Induced Aluminum Plasma in Air. Opt Laser Tech (2020) 122:105862. doi:10.1016/j. optlastec.2019.105862

29. Nagli L, Gaft M, Raichlin Y. Halogen Detection with Molecular Laser Induced Fluorescence. Spectrochimica Acta Part B: At Spectrosc (2020) 166:105813. doi:10.1016/j.sab.2020.105813

30. Fernández-Bravo Á, Delgado T, Lucena P, Laserna JJ. Vibrational Emission Analysis of the CN Molecules in Laser-Induced Breakdown Spectroscopy of Organic Compounds. Spectrochimica Acta Part B: At Spectrosc (2013) 89: 77-83. doi:10.1016/j.sab.2013.08.004

31. Harilal SS, Brumfield BE, Cannon BD, Phillips MC. Shock Wave Mediated Plume Chemistry for Molecular Formation in Laser Ablation Plasmas. Anal Chem (2016) 88:2296-302. doi:10.1021/acs.analchem.5b04136

32. Zhao YL, Lai GD, Li GG, Shang YL, Shi JC. Identifying $\mathrm{C}_{2} \mathrm{H}_{4} \mathrm{~N}_{4}$ Structural Isomers Using Fs-Laser Induced Breakdown Spectroscopy. Analyst (2020) 145: 7372-9. doi:10.1039/d0an01593h

33. Rao EN, Mathi P, Kalam SA, Sreedhar S, Singh AK, Jagatap BN, et al. Femtosecond and Nanosecond LIBS Studies of Nitroimidazoles: Correlation between Molecular Structure and LIBS Data. J Anal At. Spectrom (2016) 31: 737-50. doi:10.1039/c5ja00445d

34. Dikmelik Y, McEnnis C, Spicer JB. Femtosecond and Nanosecond LaserInduced Breakdown Spectroscopy of Trinitrotoluene. Opt Express (2008) 16: 5332-7. doi:10.1364/oe.16.005332

35. Sunku S, Gundawar MK, Myakalwar AK, Kiran PP, Tewari SP, Rao SV. Femtosecond and Nanosecond Laser Induced Breakdown Spectroscopic Studies of NTO, HMX, and RDX. Spectrochimica Acta Part B: At Spectrosc (2013) 79-80:31-8. doi:10.1016/j.sab.2012.11.002

36. Serrano J, Moros J, Laserna JJ. Sensing Signatures Mediated by Chemical Structure of Molecular Solids in Laser-Induced Plasmas. Anal Chem (2015) 87: 2794-801. doi:10.1021/acs.analchem.5b00212

37. Junjuri R, Gundawar MK. Femtosecond Laser-Induced Breakdown Spectroscopy Studies for the Identification of Plastics. J Anal At. Spectrom (2019) 34:1683-92. doi:10.1039/c9ja00102f
38. Harilal SS, Yeak J, Brumfield BE, Suter JD, Phillips MC. Dynamics of Molecular Emission Features from Nanosecond, Femtosecond Laser and Filament Ablation Plasmas. J Anal At. Spectrom (2016) 31:1192-7. doi:10. 1039/c6ja00036c

39. De Lucia FC, Jr., Gottfried JL. Influence of Molecular Structure on the LaserInduced Plasma Emission of the Explosive RDX and Organic Polymers. J Phys Chem A (2013) 117:9555-63. doi:10.1021/jp312236h

40. Shaik AK, Epuru NR, Syed H, Byram C, Soma VR. Femtosecond Laser Induced Breakdown Spectroscopy Based Standoff Detection of Explosives and Discrimination Using Principal Component Analysis. Opt Express (2018) 26:8069-83. doi:10.1364/OE.26.008069

41. Baudelet M, Boueri M, Yu J, Mao SS, Piscitelli V, Mao X, et al. Time-resolved Ultraviolet Laser-Induced Breakdown Spectroscopy for Organic Material Analysis. Spectrochimica Acta Part B: At Spectrosc (2007) 62:1329-34. doi:10.1016/j.sab.2007.10.043

42. Boueri M, Baudelet M, Yu J, Mao X, Mao SS, Russo R. Early Stage Expansion and Time-Resolved Spectral Emission of Laser-Induced Plasma from Polymer. Appl Surf Sci (2009) 255:9566-71. doi:10.1016/j.apsusc.2009.04.088

43. Camacho JJ, Diaz L, Martinez-Ramirez S, Caceres JO. Time- and SpaceResolved Spectroscopic Characterization of Laser-Induced Swine Muscle Tissue Plasma. Spectrochimica Acta Part B: At Spectrosc (2015) 111:92-101. doi:10.1016/j.sab.2015.07.008

44. Moncayo S, Marín-Roldán A, Manzoor S, Camacho JJ, Motto-Ros V, Caceres JO. Time-resolved Study of the Plasma Produced from Animal Muscle Tissue Using a Nd:YAG Laser. J Anal At. Spectrom (2018) 33:1884-91. doi:10.1039/ c8ja00258d

45. Delgado T, García-Gómez L, Cabalín LM, Laserna JJ. Detectability and Discrimination of Biomarker Organic Precursors in a Low Pressure $\mathrm{CO}_{2}$ Atmosphere by LIBS. J Anal At. Spectrom (2020) 35:1947-55. doi:10.1039/ d0ja00167h

46. Barbier S, Perrier S, Freyermuth P, Perrin D, Gallard B, Gilon N. Plastic Identification Based on Molecular and Elemental Information from Laser Induced Breakdown Spectra: a Comparison of Plasma Conditions in View of Efficient Sorting. Spectrochimica Acta Part B: At Spectrosc (2013) 88:167-73. doi:10.1016/j.sab.2013.06.007

47. Delgado T, Vadillo JM, Laserna JJ. Primary and Recombined Emitting Species in Laser-Induced Plasmas of Organic Explosives in Controlled Atmospheres. J Anal At. Spectrom (2014) 29:1675-85. doi:10.1039/c4ja00157e

48. Rother A-S, Dietz T, Kohns P, Ankerhold G. Molecular Laser-Induced Breakdown Spectroscopy for Elemental Analysis. Tm-Technisches Messen. (2017) 84:23-31. doi:10.1515/teme-2016-0032

49. Zhu Z, Li J, Guo Y, Cheng X, Tang Y, Guo L, et al. Accuracy Improvement of boron by Molecular Emission with a Genetic Algorithm and Partial Least Squares Regression Model in Laser-Induced Breakdown Spectroscopy. J Anal At. Spectrom (2018) 33:205-9. doi:10.1039/c7ja00356k

50. Guo LB, Zhu ZH, Li JM, Tang Y, Tang SS, Hao ZQ, et al. Determination of boron with Molecular Emission Using Laser-Induced Breakdown Spectroscopy Combined with Laser-Induced Radical Fluorescence. Opt Express (2018) 26:2634-42. doi:10.1364/oe.26.002634

51. Zhang W, Zhou R, Liu K, Li Q, Tang Z, Zhu C, et al. Silicon Determination in Steel with Molecular Emission Using Laser-Induced Breakdown Spectroscopy Combined with Laser-Induced Molecular Fluorescence. J Anal At. Spectrom (2021) 36:375-9. doi:10.1039/d0ja00427h

52. Tian Y, Hou S, Wang L, Duan X, Xue B, Lu Y, et al. CaOH Molecular Emissions in Underwater Laser-Induced Breakdown Spectroscopy: SpatialTemporal Characteristics and Analytical Performances. Anal Chem (2019) 91: 13970-7. doi:10.1021/acs.analchem.9b03513

53. Choi S-U, Han S-C, Lee J-Y, Yun J-I. Isotope Analysis of Iron on Structural Materials of Nuclear Power Plants Using Double-Pulse Laser Ablation Molecular Isotopic Spectrometry. J Anal At. Spectrom (2021) 36:1287-96. doi:10.1039/d1ja00097g

54. Mao X, Bol'shakov AA, Perry DL, Sorkhabi O, Russo RE. Laser Ablation Molecular Isotopic Spectrometry: Parameter Influence on boron Isotope Measurements. Spectrochimica Acta Part B: At Spectrosc (2011) 66:604-9. doi:10.1016/j.sab.2011.06.007

55. Russo RE, Bol'shakov AA, Mao X, McKay CP, Perry DL, Sorkhabi O. Laser Ablation Molecular Isotopic Spectrometry. Spectrochimica Acta Part B: At Spectrosc (2011) 66:99-104. doi:10.1016/j.sab.2011.01.007 
56. Mao X, Bol'shakov AA, Choi I, McKay CP, Perry DL, Sorkhabi O, et al. Laser Ablation Molecular Isotopic Spectrometry: Strontium and its Isotopes. Spectrochimica Acta Part B: At Spectrosc (2011) 66:767-75. doi:10.1016/j. sab.2011.12.002

57. Chirinos J, Spiliotis A, Mao X, Chan GC-Y, Russo RE, Zorba V. Remote Isotope Detection and Quantification Using Femtosecond Filament-Laser Ablation Molecular Isotopic Spectrometry. Spectrochimica Acta Part B: At Spectrosc (2021) 179:106117. doi:10.1016/j.sab.2021.106117

58. Brown S, Ford A, Akpovo CA, Johnson L. Mid-IR Enhanced Laser Ablation Molecular Isotopic Spectrometry. Spectrochimica Acta Part B: At Spectrosc (2016) 122:178-87. doi:10.1016/j.sab.2016.07.005

59. Akpovo CA, Helms L, Profeta LTM, Johnson L. Multivariate Determination of 10B Isotopic Ratio by Laser-Induced Breakdown Spectroscopy Using Multiple BO Molecular Emissions. Spectrochimica Acta Part B: At Spectrosc (2019) 162: 105710. doi:10.1016/j.sab.2019.105710

60. Dietz T, Klose J, Kohns P, Ankerhold G. Quantitative Determination of Chlorides by Molecular Laser-Induced Breakdown Spectroscopy. Spectrochimica Acta Part B: At Spectrosc (2019) 152:59-67. doi:10.1016/j. sab.2018.12.009

61. Álvarez C, Pisonero J, Bordel N. Quantification of Fluorite Mass-Content in Powdered Ores Using a Laser-Induced Breakdown Spectroscopy Method Based on the Detection of Minor Elements and CaF Molecular Bands. Spectrochimica Acta Part B: At Spectrosc (2014) 100:123-8. doi:10.1016/j. sab.2014.07.024

62. Alvarez-Llamas C, Pisonero J, Bordel N. Quantification of Fluorine Traces in Solid Samples Using CaF Molecular Emission Bands in Atmospheric Air Laser-Induced Breakdown Spectroscopy. Spectrochimica Acta Part B: At Spectrosc (2016) 123:157-62. doi:10.1016/j.sab.2016.08.006

63. Alvarez-Llamas C, Pisonero J, Bordel N. A Novel Approach for Quantitative LIBS Fluorine Analysis Using CaF Emission in Calcium-free Samples. J Anal At. Spectrom (2017) 32:162-6. doi:10.1039/c6ja00386a

64. Tang Z, Zhou R, Hao Z, Zhang W, Li Q, Zeng Q, et al. Determination of Fluorine in Copper Ore Using Laser-Induced Breakdown Spectroscopy Assisted by the SrF Molecular Emission Band. J Anal At. Spectrom (2020) 35:754-61. doi:10.1039/c9ja00407f

65. Tang Z, Hao Z, Zhou R, Li Q, Liu K, Zhang W, et al. Sensitive Analysis of Fluorine and Chlorine Elements in Water Solution Using Laser-Induced Breakdown Spectroscopy Assisted with Molecular Synthesis. Talanta (2021) 224:121784. doi:10.1016/j.talanta.2020.121784

66. Gaft M, Nagli L, Raichlin Y, Pelascini F, Panzer G, Ros VM. Laser-induced Breakdown Spectroscopy of $\mathrm{Br}$ and I Molecules with Alkali-Earth Elements. Spectrochimica Acta Part B: At Spectrosc (2019) 157:47-52. doi:10.1016/j.sab. 2019.05.003

67. De Lucia FC, Harmon RS, McNesby KL, Winkel RJ, Miziolek AW. Laserinduced Breakdown Spectroscopy Analysis of Energetic Materials. Appl Opt (2003) 42:6148-52. doi:10.1364/ao.42.006148

68. López-Moreno C, Palanco S, Javier Laserna J, DeLucia Jr F, Miziolek AW, Rose J, et al. Test of a Stand-Off Laser-Induced Breakdown Spectroscopy Sensor for the Detection of Explosive Residues on Solid Surfaces. J Anal At. Spectrom (2006) 21:55-60. doi:10.1039/b508055j

69. De Lucia FC, Jr., Gottfried JL, Munson CA, Miziolek AW. Double Pulse LaserInduced Breakdown Spectroscopy of Explosives: Initial Study towards Improved Discrimination. Spectrochimica Acta Part B: At Spectrosc (2007) 62:1399-404. doi:10.1016/j.sab.2007.10.036

70. De Lucia, Jr. FC, Jr., Gottfried JL, Munson CA, Miziolek AW. Multivariate Analysis of Standoff Laser-Induced Breakdown Spectroscopy Spectra for Classification of Explosive-Containing Residues. Appl Opt (2008) 47: G112-G121. doi:10.1364/ao.47.00g112

71. Moros J, Serrano J, Sánchez C, Macías J, Laserna JJ. New Chemometrics in Laser-Induced Breakdown Spectroscopy for Recognizing Explosive Residues. $J$ Anal At. Spectrom (2012) 27:2111-22. doi:10.1039/c2ja30230f

72. Yang CS-C, Jin F, Trivedi SB, Brown EE, Hommerich U, Tripathi A, et al. Long-wave Infrared (LWIR) Molecular Laser-Induced Breakdown Spectroscopy (LIBS) Emissions of Thin Solid Explosive Powder Films Deposited on Aluminum Substrates. Appl Spectrosc (2017) 71:728-34. doi:10.1177/0003702817696089

73. Farhadian AH, Tehrani MK, Keshavarz MH, Karimi M, Darbani SMR, Rezayi AH. A Novel Approach for Investigation of Chemical Aging in Composite
Propellants through Laser-Induced Breakdown Spectroscopy (LIBS). J Therm Anal Calorim (2015) 124:279-86. doi:10.1007/s10973-015-5116-9

74. Farhadian AH, Tehrani MK, Keshavarz MH, Karimi M, Reza Darbani SM. Relationship between the Results of Laser-Induced Breakdown Spectroscopy and Dynamical Mechanical Analysis in Composite Solid Propellants during Their Aging. Appl Opt (2016) 55:4362-9. doi:10.1364/ao.55.004362

75. El-Hussein A, Marzouk A, Harith MA. Discriminating Crude Oil Grades Using Laser-Induced Breakdown Spectroscopy. Spectrochimica Acta Part B: At Spectrosc (2015) 113:93-9. doi:10.1016/j.sab.2015.09.002

76. Anzano J, Lasheras R-J, Bonilla B, Casas J. Classification of Polymers by Determining of $\mathrm{C} 1: \mathrm{C} 2: \mathrm{CN}: \mathrm{H}: \mathrm{N}: \mathrm{O}$ Ratios by Laser-Induced Plasma Spectroscopy (LIPS). Polym Test (2008) 27:705-10. doi:10.1016/j. polymertesting.2008.05.012

77. Costa VC, Aquino FWB, Paranhos CM, Pereira-Filho ER. Identification and Classification of Polymer E-Waste Using Laser-Induced Breakdown Spectroscopy (LIBS) and Chemometric Tools. Polym Test (2017) 59:390-5. doi:10.1016/j.polymertesting.2017.02.017

78. Banaee M, Tavassoli SH. Discrimination of Polymers by Laser Induced Breakdown Spectroscopy Together with the DFA Method. Polym Test (2012) 31:759-64. doi:10.1016/j.polymertesting.2012.04.010

79. Gottfried JL. Discrimination of Biological and Chemical Threat Simulants in Residue Mixtures on Multiple Substrates. Anal Bioanal Chem (2011) 400: 3289-301. doi:10.1007/s00216-011-4746-4

80. Baudelet M, Guyon L, Yu J, Wolf J-P, Amodeo T, Fréjafon E, et al. Spectral Signature of Native CN Bonds for Bacterium Detection and Identification Using Femtosecond Laser-Induced Breakdown Spectroscopy. Appl Phys Lett (2006) 88:063901. doi:10.1063/1.2170437

81. Baudelet M, Guyon L, Yu J, Wolf J-P, Amodeo T, Fréjafon E, et al. Femtosecond Time-Resolved Laser-Induced Breakdown Spectroscopy for Detection and Identification of Bacteria: A Comparison to the Nanosecond Regime. J Appl Phys (2006) 99:084701. doi:10.1063/1.2187107

82. Yang CSC, Jin F, Swaminathan SR, Patel S, Ramer ED, Trivedi SB, et al. Comprehensive Study of Solid Pharmaceutical Tablets in Visible, Near Infrared (NIR), and Longwave Infrared (LWIR) Spectral Regions Using a Rapid Simultaneous Ultraviolet/visible/NIR (UVN) + LWIR Laser-Induced Breakdown Spectroscopy Linear Arrays Detection System and a Fast AcoustoOptic Tunable Filter NIR Spectrometer. Opt Express (2017) 25:26885-97. doi:10.1364/oe.25.026885

83. Kotzagianni M, Kakkava E, Couris S. Laser-induced Breakdown Spectroscopy (LIBS) for the Measurement of Spatial Structures and Fuel Distribution in Flames. Appl Spectrosc (2016) 70:627-34. doi:10.1177/0003702816631296

84. Li S, Li Y, Shi Z, Sui L, Li H, Li Q, et al. Fluorescence Emission Induced by the Femtosecond Filament Transmitting through the Butane/air Flame. Spectrochimica Acta A: Mol Biomol Spectrosc (2018) 189:32-6. doi:10.1016/j.saa.2017.08.006

85. Kalam SA, Murthy NL, Mathi P, Kommu N, Singh AK, Rao SV. Correlation of Molecular, Atomic Emissions with Detonation Parameters in Femtosecond and Nanosecond LIBS Plasma of High Energy Materials. J Anal At. Spectrom (2017) 32:1535-46. doi:10.1039/c7ja00136c

86. Gottfried JL. Laser-induced Plasma Chemistry of the Explosive RDX with Various Metallic Nanoparticles. Appl Opt (2012) 51:B13-B21. doi:10.1364/Ao. $51.000 \mathrm{~b} 13$

Conflict of Interest: The authors declare that the research was conducted in the absence of any commercial or financial relationships that could be construed as a potential conflict of interest.

Publisher's Note: All claims expressed in this article are solely those of the authors and do not necessarily represent those of their affiliated organizations, or those of the publisher, the editors, and the reviewers. Any product that may be evaluated in this article, or claim that may be made by its manufacturer, is not guaranteed or endorsed by the publisher.

Copyright $\odot 2022 \mathrm{Xu}, \mathrm{Ma}$, Zhao and Dong. This is an open-access article distributed under the terms of the Creative Commons Attribution License (CC BY). The use, distribution or reproduction in other forums is permitted, provided the original author(s) and the copyright owner(s) are credited and that the original publication in this journal is cited, in accordance with accepted academic practice. No use, distribution or reproduction is permitted which does not comply with these terms. 